\title{
Microstructuring of Transparent Dielectric Films by TWIN-LIBWE Method for OWLS Applications
}

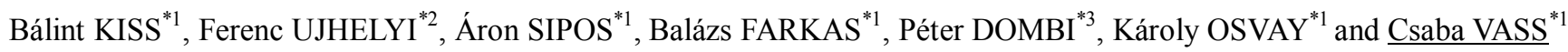 \\ ${ }^{* 1}$ Department of Optics and Quantum Electronics, University of Szeged, H-6720 Szeged, Dóm tér 9, \\ Hungary \\ E-mail: vasscsaba@physx.u-szeged.hu \\ ${ }^{* 2}$ Department of Atomic Physics, Physical Institute, Budapest University of Technology and Eco- \\ nomics, H-1111 Budapest, Budafoki út 8, Hungary \\ ${ }^{*}$ Wigner Research Centre for Physics, Hungarian Academy of Sciences, H-1121 Budapest, Konko- \\ ly-Thege M. út 29-33, Hungary
}

\begin{abstract}
We report on the fabrication of micro- and submicrometer period transmission gratings in $\mathrm{SiO}_{2}$, $\mathrm{Al}_{2} \mathrm{O}_{3}$, and $\mathrm{Y}_{2} \mathrm{O}_{3}$ thin films by two-beam interferometric laser-induced backside wet etching (TWIN-LIBWE). The optimal etching parameter domain has been established for each film with the help of profilometric and atomic force microscopic measurements. The modulation depth and the quality of the etched $\mathrm{SiO}_{2}$ film is found excellent over a relatively broad fluence $\left(285-600 \mathrm{~mJ} / \mathrm{cm}^{2}\right)$ and pulse quantity (1-150) range. For $\mathrm{Al}_{2} \mathrm{O}_{3}$, and $\mathrm{Y}_{2} \mathrm{O}_{3}$ films it is significantly narrower (250-260 $\mathrm{mJ} / \mathrm{cm}^{2}$ and 1-10 pulses). We have tested the created gratings as waveguide couplers, which prove the suitability of the studied method to produce transmission gratings onto dielectric films.
\end{abstract}

DOI: 10.2961/jlmn.2013.03.0014

Keywords: TWIN-LIBWE, grating, thin film, waveguide

\section{Introduction}

Transparent thin films are widely used in many areas from optics through medicine to industry as high reflective and antireflective coatings, beam splitters, etc. Several applications need structured thin films deposited on bulk dielectric with a resolution of micrometer or even submicrometer. Especially, Optical Waveguide Lightmode Spectroscopy (OWLS) [1,2] is based on the coupling of a laser beam into a planar waveguide via a diffraction grating.

Dielectric thin films which are transparent in broad wavelength range (including ultraviolet region) can in principle be machined and structured by techniques developed for bulk transparent materials (fused silica, sapphire, $\mathrm{MgF}_{2}$, $\mathrm{CaF}_{2}, \mathrm{BaF}_{2}$, etc.). Reactive ion etching (RIE) provides the most outstanding resolution and surface quality at submicrometer scale, but it is a complicated and rather expensive procedure [3]. Recently, RIE has been successfully used for high quality microstructuring diamond like carbon (DLC) thin films [4]. Considering laser based techniques, $10 \mu \mathrm{m}$ period gratings in germanosilicate film were created by both pulsed and cw direct UV writing [5], while coupling transmission gratings for solar cells were fabricated in $\mathrm{ZnO}_{2}$ film by photolithography [6]. Moreover, Franc [7] and Beinhorn [8] reported submicron period grooved structures by holographic and projection imaging method, respectively.

Laser based indirect methods are also candidates for machining of transparent dielectrics. Upon these techniques a liquid or solid material having high absorptivity at the laser wavelength is attached to the target. This assembly is irradiated from the transparent target side. Hence the laser energy is absorbed by the material which makes the target back surface etched via thermal and/or plasma mediated processes. Among these procedures the laser-induced back- side wet etching (LIBWE) method, where the backside of the transparent target is in contact with a liquid absorber [915], may provide the most flexibility to apply it. The most promising ways to sub-micron period grating fabrication in bulk targets by LIBWE is the mask projection technique $[15,16]$, and the combination of LIBWE with the two-beam interferometric method (TWIN-LIBWE) [17-20].

In this paper we report on our first experiments to produce and characterize micrometer period surface relief gratings in $\mathrm{SiO}_{2}, \mathrm{Al}_{2} \mathrm{O}_{3}$, and $\mathrm{Y}_{2} \mathrm{O}_{3}$ thin films by TWINLIBWE technique. To the best of our knowledge, micrometer period grating has not been fabricated into dielectric film by any of the indirect laser-based methods yet.

\section{Experimental}

In TWIN-LIBWE two coherent laser beams are arranged to overlap both spatially and temporally at the back side of the sample, in order to interfere with each other. In this setup a spatially double-filtered beam of a Q-switched frequency-quadrupled Nd:YAG laser (s-polarized; $\lambda=266$ $\mathrm{nm} ; 8 \mathrm{~ns}$; repetition rate: $10 \mathrm{~Hz}$ ) was used. More details can be found in our previous study [20]. The period of gratings presented in this paper is measured to be $1010 \mathrm{~nm}$. During the experiments, the number of laser pulses varied between 1 and 150 , while the laser fluence was altered between 200 and $600 \mathrm{~mJ} / \mathrm{cm}^{2}$. The transparent thin films have been deposited on fused silica plates (thickness $1 \mathrm{~mm}$ ). Three dielectric materials were used with various thicknesses: 200 $\mathrm{nm}$ thick films of $\mathrm{SiO}_{2}$ and $\mathrm{Y}_{2} \mathrm{O}_{3}, 300 \mathrm{~nm}$ of $\mathrm{Al}_{2} \mathrm{O}_{3}$, moreover 800 and $1000 \mathrm{~nm}$ thick films of $\mathrm{SiO}_{2}$ and $\mathrm{Al}_{2} \mathrm{O}_{3}$, respectively. The $\mathrm{SiO}_{2}$ and $\mathrm{Al}_{2} \mathrm{O}_{3}$ films were prepared by electrongun based reactive evaporation. The $\mathrm{Y}_{2} \mathrm{O}_{3}$ thin films on fused silica substrate were produced by Altechna Co.Ltd. 
Refractive index, extinction coefficient and film thickness were determined by spectroscopic ellipsometry. The measurements were performed by a Semilab Sopra GES$5 \mathrm{E}$ rotating polarizer ellipsometer within the spectral range of 245-1000 $\mathrm{nm}$ at different angle of incidences between $52^{\circ}$ and $62^{\circ}$. A three phase model (fused silica substrate, thin film and ambient) was considered to fit the measured ellipsometric data. The refractive index of the quartz substrates was taken from the Sellmeier dispersion relation [21]. The small absorption of the films was modeled with Lorentz oscillators.

The irradiated surfaces were studied in three steps. First, the etched areas were scanned by Dektak 8 profilometer (tip radius: $2.5 \mu \mathrm{m}$ ) to determine the etch depth (ED). Second, the morphologies of gratings were studied by a PSIA XE-100 atomic force microscope (AFM) to learn the modulation depth (MD) and the overall morphology of the etched surfaces. These information together helped to decide whether the gratings were produced solely into the films, or also partially into the fused silica substrate. This work is focusing on the structures which etched into the films only, leaving the substrate unetched under them. The gratings must fulfill this condition to be able to couple the light into the waveguide layer.

\section{Results}

\subsection{Micrometer period grating fabrication}

In our first experimental series reference gratings were produced in bulk fused silica by TWIN-LIBWE (figure 1). The uncoated substrates were taken from the same batch as the coated ones.

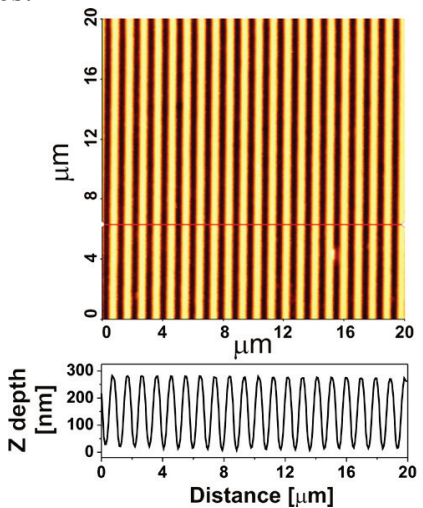

Fig. 1 AFM image of the grating $(\mathrm{p}=1 \mu \mathrm{m})$ in bulk fused silica plate

$\mathrm{F}=390 \mathrm{~mJ} / \mathrm{cm}^{2}, 75$ laser pulses

In all presented cases the laser parameters were adjusted to produce grating on the level of the original surface, so the ED was negligible. According to our previous results [20], this provides the best grating quality.

In our first thin film structuring experiments $\mathrm{SiO}_{2}$ films were used as target. Since it has the same material as the substrate, it was important to check whether the LIBWE process is suitable for fabrication of crack and debris-free surfaces into film without their complete removal from the substrate. The gratings in figure 2(a) and 2(b) are etched in $200 \mathrm{~nm}$ and $800 \mathrm{~nm}$ thick film, while the MD was measured to be $100 \mathrm{~nm}$ and $320 \mathrm{~nm}$, respectively. According to our AFM scans the grating structure in the $\mathrm{SiO}_{2}$ thin film is well defined; the cross-section profile is regular and there are not any signs of cracks, debris on the film.
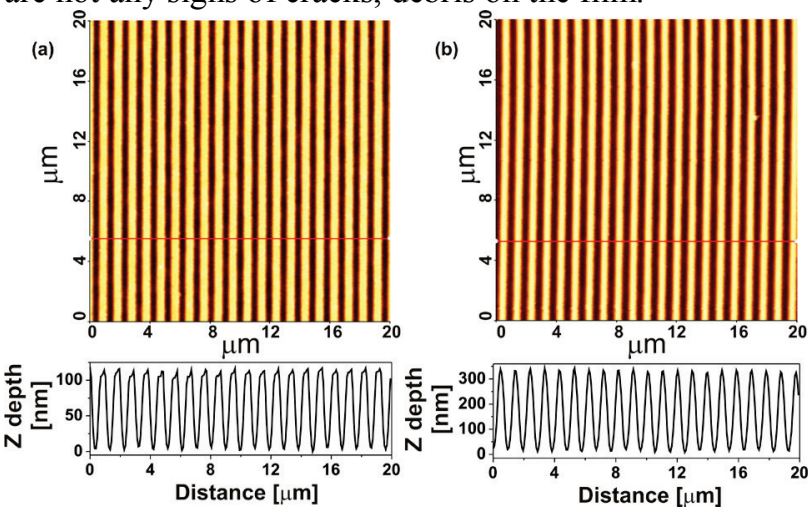

Fig. 2 AFM images of gratings $(p=1 \mu \mathrm{m})$ in $\mathrm{SiO}_{2}$ thin films

(a) film thickness $200 \mathrm{~nm}, \mathrm{~F}=375 \mathrm{~mJ} / \mathrm{cm}^{2}, 30$ pulses

(b) film thickness $800 \mathrm{~nm}, \mathrm{~F}=315 \mathrm{~mJ} / \mathrm{cm}^{2}, 100$ pulses

Since the substrates were proven to be unetched under the films, we can conclude that the gratings were etched completely into the $\mathrm{SiO}_{2}$ thin films. The MD of gratings in $\mathrm{SiO}_{2}$ film was easily adjustable from few nanometers to hundreds of nanometers (figure 3), similarly to the case of bulk $\mathrm{SiO}_{2}$ target (see figure 6(a) in reference [20]).

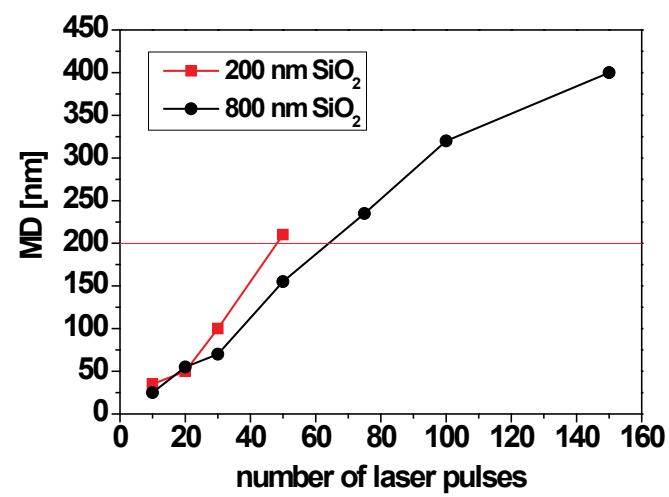

Fig. 3 The MD of gratings $(p=1 \mu \mathrm{m})$ etched in $\mathrm{SiO}_{2}$ films at various pulses $\left(\mathrm{F}=320 \mathrm{~mJ} / \mathrm{cm}^{2}\right)$

In order to operate as a light coupler device the refractive index of the film must be higher than the substrate's. Sapphire and yttrium-oxide are appropriate materials in this regard. In case of sapphire films the optimal fluence was found around $260 \mathrm{~mJ} / \mathrm{cm}^{2}$, just above the $240 \mathrm{~mJ} / \mathrm{cm}^{2}$ threshold and maximum 10 pulses resulted the best surfaces. Increasing the fluence to $300 \mathrm{~mJ} / \mathrm{cm}^{2}$ caused the complete removal of the $300 \mathrm{~nm}$ thick film from the substrate by 1-2 pulses, and the cracking of the $1000 \mathrm{~nm}$ film even at low pulse numbers (4-6). Considering the $300 \mathrm{~nm}$ thick sapphire film, the MD of gratings increases from $\sim 5$ to $\sim 20$ nm by 1 to 3 pulses (figure 4(a)). Further pulses remove the film completely in intensity maximums, and the substrate is also etched. 

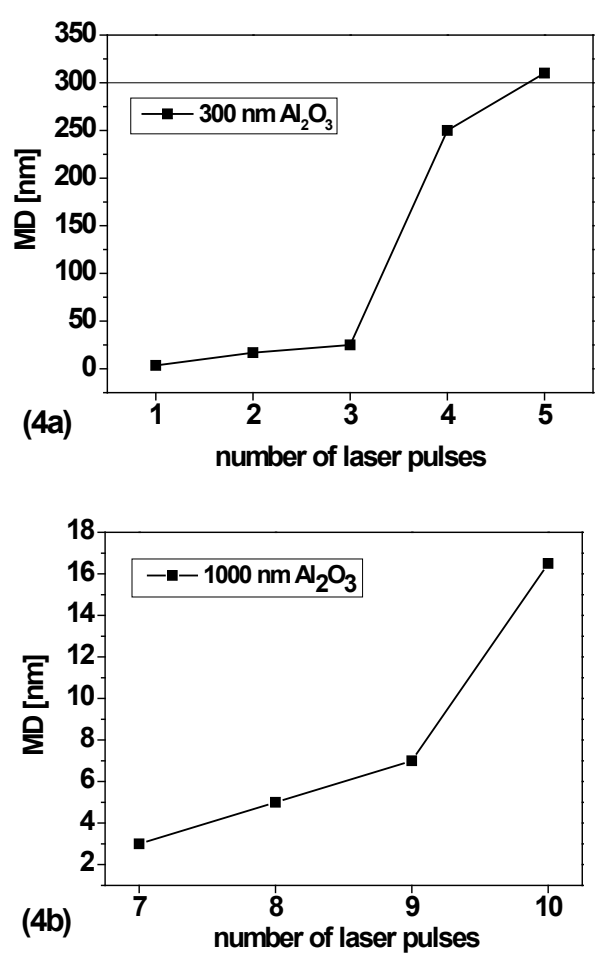

Fig. 4 The MD of gratings $(\mathrm{p}=1 \mu \mathrm{m})$ etched in $\mathrm{Al}_{2} \mathrm{O}_{3}$ films at various pulses

(a) film thickness $300 \mathrm{~nm}, \mathrm{~F}=260 \mathrm{~mJ} / \mathrm{cm}^{2}$

(b) film thickness $1000 \mathrm{~nm}, \mathrm{~F}=250 \mathrm{~mJ} / \mathrm{cm}^{2}$

In case of thicker $(1000 \mathrm{~nm}) \mathrm{Al}_{2} \mathrm{O}_{3}$ film grooves are not observable below 6 pulses then the MD increases from $~ 3-$ $6 \mathrm{~nm}$ to $\sim 20 \mathrm{~nm}$ using 7 to 10 pulses at $250 \mathrm{~mJ} / \mathrm{cm}^{2}$ (figure 4(b)). Above 10 pulses cracks appear in the irradiated area. For sapphire films we found the optimal fabrication parameter set (laser fluence, number of laser pulses) to be significantly narrower than in case of $\mathrm{SiO}_{2}$ films and bulk. The MD of gratings is altering between 17-20 nm and 15-18 nm in figure 5(a) and 5(b), respectively.
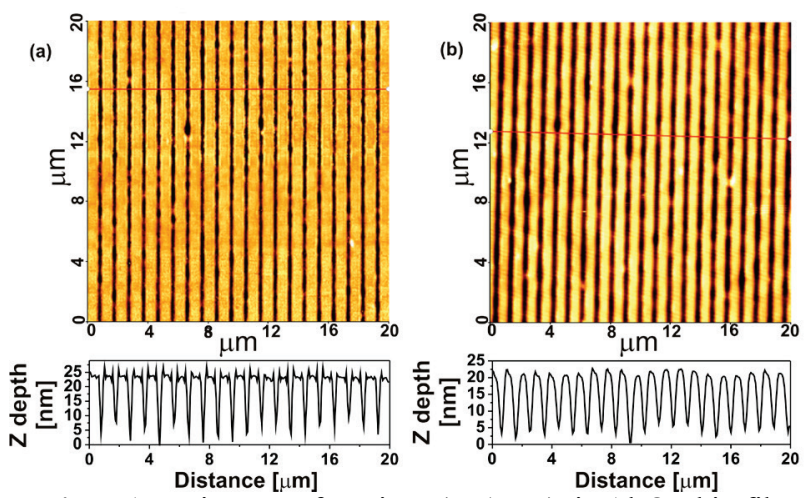

Fig. 5 AFM images of gratings $(p=1 \mu \mathrm{m})$ in $\mathrm{Al}_{2} \mathrm{O}_{3}$ thin films

(a) film thickness $300 \mathrm{~nm}, \mathrm{~F}=260 \mathrm{~mJ} / \mathrm{cm}^{2}, 3$ pulses

(b) film thickness $1000 \mathrm{~nm}, \mathrm{~F}=250 \mathrm{~mJ} / \mathrm{cm}^{2}, 10$ pulses

The etching behavior of $\mathrm{Al}_{2} \mathrm{O}_{3}$ films is noticeably depends on the film thickness. The temperature difference between the two sides of the film is higher in case of thicker film, and the consequently arising mechanical stress could cause the cracking of deposited film above 10 pulses. Considering $\mathrm{Y}_{2} \mathrm{O}_{3}$ film, clear grooved structure does not evolves below 7-8 pulses at $260 \mathrm{~mJ} / \mathrm{cm}^{2}$ fluence. Only around 8-9 pulses the material removal at intensity maximums is completed and the grooves become clear as it is illustrated in figure 6 . Above 9 pulses the substrate material also etched. For this reason, plotting the MD versus the number of pulses is unnecessary.
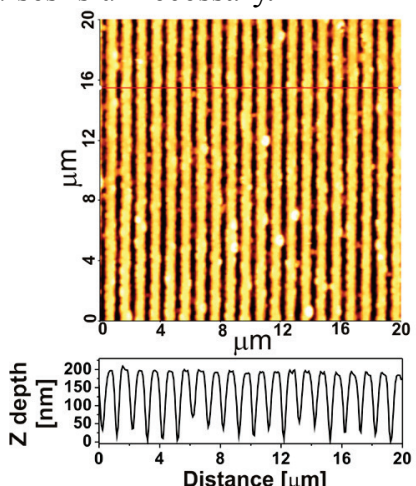

Fig. 6 AFM image of grating $(\mathrm{p}=1 \mu \mathrm{m})$ in $200 \mathrm{~nm}$ thick $\mathrm{Y}_{2} \mathrm{O}_{3}$ thin film, $\mathrm{F}=260 \mathrm{~mJ} / \mathrm{cm}^{2}, 8$ pulses

\subsection{Submicrometer period grating fabrication}

According to reference [2] higher periodicity gratings $(\mathrm{p} \leq 500 \mathrm{~nm})$ and few hundred nanometers thick films are the most suitable for sensitive OWLS application. For these reason gratings with period around half of micrometer $(\mathrm{p}=470 \mathrm{~nm})$ were also fabricated in sapphire and yttriumoxide films (figure 7).

In the optimum case the irradiated $300 \mathrm{~nm}$ sapphire film (figure $7(\mathrm{a})$ ) exhibits $\approx 10 \mathrm{~nm} \mathrm{MD}$ with regular morphology. The MD grows monotonously (figure 7(b)) from $1.5 \mathrm{~nm}$ ( 4 pulses) to $8.5 \mathrm{~nm}$ ( 8 pulses). Above 8 pulses the surface becomes completely irregular and no grooves are observable while more than 15 pulses are resulted in the complete removal of film from the illuminated area.
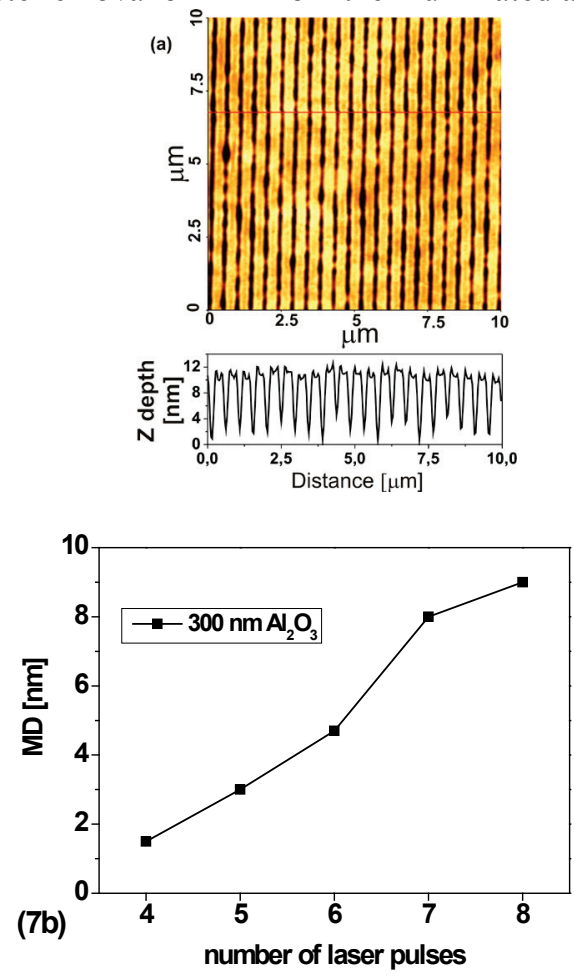

Fig. 7

(a) AFM images and (b) MD versus number of laser pulses of grating $(\mathrm{p}=470 \mathrm{~nm})$ in $300 \mathrm{~nm}$ thick $\mathrm{Al}_{2} \mathrm{O}_{3}$ thin film, $\mathrm{F}=260$ $\mathrm{mJ} / \mathrm{cm}^{2}, 8$ pulses 
In case of decreased grating period the overall surface quality of etched $\mathrm{Y}_{2} \mathrm{O}_{3}$ is significantly lower compare to sapphire. However the formation of this rough periodic structure (figure 8 ) is occurs within a narrow (1 to 3 ) pulse range, it is suitable for light coupler grating.

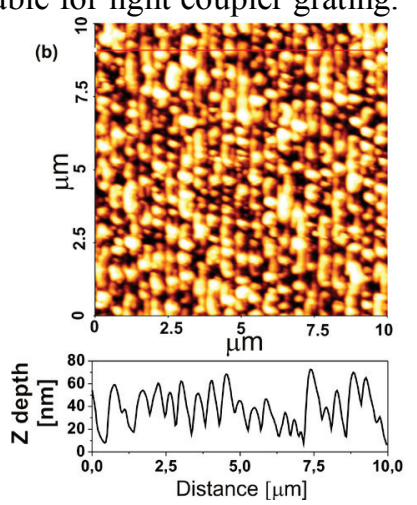

Fig 8. AFM images of grating $(p=470 \mathrm{~nm})$ in $200 \mathrm{~nm}$ thick $\mathrm{Y}_{2} \mathrm{O}_{3}$ thin film, $\mathrm{F}=260 \mathrm{~mJ} / \mathrm{cm}^{2}, 3$ pulses

\subsection{Demonstration of light coupling}

According to our purpose figure 9 illustrates two of the grating as successfully incouples the light of He-Ne laser $(\lambda=632,8 \mathrm{~nm})$ into the sapphire and yttrium-oxide film. The horizontal red line is the TE light mode propagating in the film. It confirms that TWIN-LIBWE made diffraction gratings are suitable for waveguide applications.

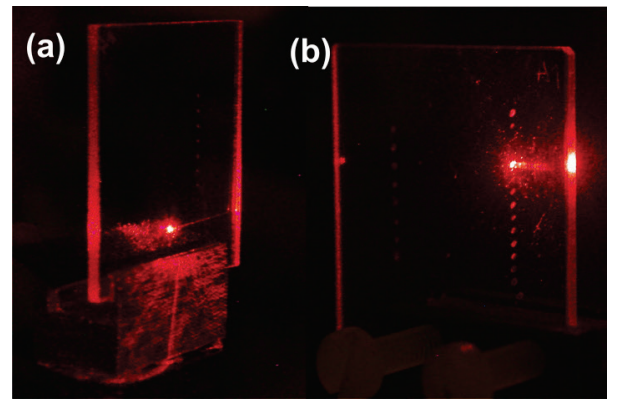

Fig. 9 Photography of the incoupled $\mathrm{HeNe}$ light into films (a) $1000 \mathrm{~nm} \mathrm{Al}_{2} \mathrm{O}_{3}, \mathrm{p}=1 \mu \mathrm{m}, \mathrm{MD}=16,5 \mathrm{~nm}$ (avg). (b) $200 \mathrm{~nm} \mathrm{Y}_{2} \mathrm{O}_{3}, \mathrm{p}=470 \mathrm{~nm}, \mathrm{MD}=15 \mathrm{~nm}$ (avg)

\section{Discussion}

To compare the surface quality of the presented gratings, a quantitative analysis was carried out. The quality of a surface usually can be characterized by its surface roughness ( $\mathrm{Ra}$ ) and in our case by the combination of Fourierfiltering and roughness calculation. First the AFM data was Fourier-filtered at a cutoff frequency corresponding to the wavelength of $2 p$, and then the roughness of low-pass filtered data was calculated. This method reveals the waviness of gratings [18], which is below $10 \mathrm{~nm}$ in these optimized cases (Table 1) in agreement what we measured before [20]. The waviness cannot describe the irregularity along the grooves, the deviation from a straight line, which can be observed at the sides of grooves (e.g. figure 4). A new parameter (groove irregularity factor) is introduced which based on the fact that the irregularities can be characterized by the Ra parameter as follows. The Ra of line section parallel to each groove at the half maximum of modulation profile was determined, then the average of these values were divided by the corresponding MD (Table $1)$.

The groove irregularity factors of gratings in $\mathrm{SiO}_{2}$ films are higher than the bulk's, but definitely lower than in the other cases. It is in agreement with the first expression one can get by taking a look at the AFM topographies.

\begin{tabular}{cccccccc}
\multicolumn{8}{c}{ Table 1 The parameters of the presented gratings } \\
$\begin{array}{c}\text { Grating } \\
\text { period } \\
{[\mathrm{nm}]}\end{array}$ & $\begin{array}{c}\text { Film } \\
\text { Material } \\
\text { thickness } \\
{[\mathrm{nm}]}\end{array}$ & $\begin{array}{c}\text { Fluence } \\
{\left[\mathrm{mJ} / \mathrm{cm}^{2}\right]}\end{array}$ & $\begin{array}{c}\text { Number } \\
\text { of laser } \\
\text { pulses }\end{array}$ & $\begin{array}{c}\text { Modulation } \\
\text { depth (avg) } \\
{[\mathrm{nm}]}\end{array}$ & $\begin{array}{c}\text { Waviness } \\
{[\mathrm{nm}]}\end{array}$ & $\begin{array}{c}\text { Groove } \\
\text { irregularity } \\
\text { factor }\end{array}$ \\
\hline & $\mathrm{SiO}_{2}$ bulk & - & 390 & 75 & 265 & 2.81 & 0.026 \\
& & 200 & 375 & 30 & 100 & 2.32 & 0.083 \\
\multirow{2}{*}{1010} & $\mathrm{SiO}_{2}$ & 800 & 315 & 100 & 320 & 4.79 & 0.071 \\
& & 300 & 260 & 3 & 18.5 & 0.61 & 0.227 \\
& $\mathrm{Al}_{2} \mathrm{O}_{3}$ & 1000 & 250 & 10 & 16.5 & 1.08 & 0.170 \\
& $\mathrm{Y}_{2} \mathrm{O}_{3}$ & 200 & 260 & 8 & 190 & 9.23 & 0.136 \\
\hline \multirow{2}{*}{470} & $\mathrm{Al}_{2} \mathrm{O}_{3}$ & 300 & 260 & 8 & 8.5 & 0.54 & 0.211 \\
& $\mathrm{Y}_{2} \mathrm{O}_{3}$ & 200 & 260 & 3 & 15 & 4.63 & 0.790 \\
\hline
\end{tabular}

The most important conclusions upon thin film fabrication by TWIN-LIBWE are the followings. The etching of $\mathrm{SiO}_{2}$ films are very similar to what we have experienced for bulk amorphous $\mathrm{SiO}_{2}$ target: high quality gratings can be etched in broad fluence $\left(285-600 \mathrm{~mJ} / \mathrm{cm}^{2}\right)$ and pulse quantity (1-150) intervals, so the MD is easily controllable. The reasonable fluence and pulse number domain of $\mathrm{Al}_{2} \mathrm{O}_{3}$ and $\mathrm{Y}_{2} \mathrm{O}_{3}$ films were significantly narrower. Best results achieved when the fluence was just above the threshold $\left(250-260 \mathrm{~mJ} / \mathrm{cm}^{2}\right)$ and only a few pulses (1-10) are applied. The TWIN-LIBWE threshold fluence of $\mathrm{SiO}_{2}$ films is found to be equal to the bulk's value: $285 \mathrm{~mJ} / \mathrm{cm}^{2}$, while in case of $\mathrm{Al}_{2} \mathrm{O}_{3}$ and $\mathrm{Y}_{2} \mathrm{O}_{3}$ films it is 240 and $220 \mathrm{~mJ} / \mathrm{cm}^{2}$, respectively. Decreasing the laser fluence to $200 \mathrm{~mJ} / \mathrm{cm}^{2}$ resulted unetched surfaces on all films.

Spectroscopic ellipsometric investigations were carried out to learn the optical properties of non-etched films, focusing on the absorption at $266 \mathrm{~nm}$ wavelength. The optical features of $\mathrm{SiO}_{2}$ films are proved to be identical to bulk fused silica, which explains the excellent quality and scalability we have experienced. According to these measurements, the absorption coefficients of $\mathrm{Al}_{2} \mathrm{O}_{3}$ and $\mathrm{Y}_{2} \mathrm{O}_{3}$ films in laser wavelength are rather low (less than few hundred $\mathrm{cm}^{-1}$ ), therefore in case of these films the absorbed energy is negligible and the overall quality of optimized gratings is found to be suitable for waveguide applications.

Besides absorption, the thermal effects (heat diffusion, intense warming up and melting) and the consequences of those (high pressure bubble expansion, the arising mechanical stress) and etched surface contamination play significant role in LIBWE. The importance of the mechanical stress is clearly expressed for the two phase system: the different material properties lead to higher stress between the substrate and films than in pure bulk target cases (e.g. the cracking of the sapphire film). These effects contribute to the narrowing optimal experimental parameter set. The investigation and discussion of the destructive effects on thin film fabrication are beyond the aims of this particular study, since our main aim was to found the optimal etching parameters set and demonstrate that even half of microme- 
ter period gratings can be fabricated in UV-transparent thin films by this indirect laser etching technique.

\section{Summary}

We have fabricated micro- and submicrometer resolution periodic structures in transparent dielectric thin films deposited onto fused silica substrates by TWIN-LIBWE method. The modulation depth and the quality of the etched $\mathrm{SiO}_{2}$ films were comparable to bulk fused silica. The fabrication of $\mathrm{Al}_{2} \mathrm{O}_{3}$ and $\mathrm{Y}_{2} \mathrm{O}_{3}$ films appeared to happen within a narrower parameter range. The suitability of the presented gratings as light couplers for waveguide applications has been demonstrated. According to our results, the use of TWIN-LIBWE may open a new promising route for microfabrication of dielectric thin films required by sensing and spectroscopic applications.

\section{Acknowledgments}

The authors gratefully acknowledge the financial support of Hungarian Scientific Research Fund (OTKA PD 104477). This research was supported by the European Union and the State of Hungary, co-financed by the European Social Fund in the framework of TÁMOP 4.2.4. A/211-1-2012-0001 'National Excellence Program. The project was subsidized by the European Union and co-financed by the European Social Fund. The project was partially funded by „TÁMOP-4.2.2.A-11/1/KONV-2012-0060 - „Impulse lasers for use in materials science and biophotonics" is supported by the European Union and co-financed by the European Social Fund.

\section{References}

[1] J. Voros, R. Graf, G.L. Kenausis, A. Bruinink, J. Mayer, M. Textor, E. Wintermantel and N.D. Spencer: Biosens. Bioelectron., 15, (2000) 423.

[2] J. Voros, J.J. Ramsden, G. Csucs, I. Szendro, S.M. De Paula, M. Textora and N.D. Spencer: Biomaterials, 23, (2002) 3699.

[3] X. Li, T.Abe and M. Esashi: Sensors Actuat A-Phys., 87, (2001) 139.

[4] G. A Cirino., R. D. Mansano, P. Verdonck, R. G. Jasinevicius and L. G. Neto: Surf. Coat. Tech., 204, (2010) 2966.

[5] A. D. Razafimahatratra, M. Benatsou, M. Bouazaoui, W. X. Xie, C. Mathieu, A. Dacosta and M. Douay: Opt. Mater, 13, (2000) 439.

[6] H. Stiebig, N. Senoussaoui, T. Brammer and J. Muller: Sol. Energ. Mat. Sol. C., 90, (2006) 3031.

[7] J. Franc, V. Barnier, F. Vocanson, E. Gamet, M. Lesage, D. Jamon and Y. Jourlin: Thin Solid Films, $520,(2012) 6050$.

[8] F. Beinhorn, J. Ihlemann, P. Simon, G. Marowsky, B. Maisenhoelder, J. Edlinger, D. Neuschaefer and D. Anselmetti: Appl. Surf. Sci., 138-139, (1999) 107.

[9] J. Wang, H. Niino and A. Yabe: Appl. Phys. A-Mater, 68, (1999) 111.

[10] S. I. Dolgaev, A. A. Lyalin, A. V. Simakin, V. V. Vronov and G. A. Shafeev: Appl. Surf. Sci., 109/110, (1997) 201.

[11] Cs. Vass, J. Budai, Z. Schay and B. Hopp: JLMN, Vol. 5, No. 1, (2010) 43.
[12] G. Kopitkovas, T. Lippert, C. David, S. Canulescu, A. Wokaun and J. Gobrecht: J. . Photoch.. and Photobio.. A, 166, (2004) 135.

[13] J. Y. Cheng, M. H. Yen, C. W. Wei, Y. C. Chuang and T. H. Young: J. Micromech. Microeng., 15, (2005) 1147.

[14]Z. Q. Huang, M. H. Hong, K. S. Tiaw and Q. Y. Lin: JLMN, Vol. 2, No. 3, (2007) 194.

[15] K. Zimmer, R. Böhme, A. Braun, B. Rauschenbach and F. Bigl: Appl. Phys. A-Mater, 74, (2002) 453.

[16] X. Ding, Y. Kawaguchi, T. Sato, A. Narazaki, R. Kurosaki and H. Niino: J. Photochem. Photobio. A, 166, (2004) 129.

[17] Cs. Vass, K. Osvay, M. Csete and B. Hopp: Appl. Surf. Sci., 253, (2007) 8059.

[18] Cs. Vass, K. Osvay and B. Hopp: Opt. Express, Vol. 14, No. 18, (2006) 8354.

[19] Cs. Vass, K. Osvay, B. Hopp and Zs. Bor: Appl Phys A-Mater, 87, (2007) 611.

[20] Cs. Vass, K. Osvay, T. Véső and B. Hopp: Appl Phys A-Mater, 93, (2008) 69.

[21] H.G. Tompkins, E.A. Irene (Eds.): "Handbook of Ellipsometry”, (William Andrew/Springer, Berlin , 2005)

(Received: July 20, 2013, Accepted: December 2, 2013) 